\title{
Micro-targeting, the quantified persuasion
}

\section{Daniel Kreiss}

School of Media and Journalism, University of North Carolina at Chapel Hill, United States of America

Published on 30 Dec 2017 | DOI: 10.14763/2017.4.774

\begin{abstract}
During the past three decades there has been a persistent, and dark, narrative about political micro-targeting. But while it might seem that the micro-targeting practices of campaigns have massive, and un-democratic, electoral effects, decades of work in political communication should give us pause. What explains the outsized concerns about microtargeting in the face of the generally thin evidence of its widespread and pernicious effects? This essay argues that we have anxieties about micro-targeting because we have anxieties about democracy itself. Or, to put it differently, that scholars often hold up an idealised vision of democracy as the standard upon which to judge all political communication.
\end{abstract}

Keywords: Democracy, Elections, Micro-targeting, Social media

\section{Article information}

\section{Received: 01 Nov 2017 Published: 30 Dec 2017}

Licence: Creative Commons Attribution 3.0 Germany

Competing interests: The author has declared that no competing interests exist that have influenced the text.

URL: http://policyreview.info/articles/analysis/micro-targeting-quantified-persuasion

Citation: Kreiss, D. (2017). Micro-targeting, the quantified persuasion. Internet Policy Review, 6(4). https://doi.org/10.14763/2017.4.774

This guest essay is part of Political micro-targeting, a special issue of Internet Policy Review guest-edited by Balázs Bodó, Natali Helberger, and Claes H. de Vreese.

Disclaimer: it has not been peer reviewed. It is treated here as a reflection.

During the past three decades there has been a persistent, and dark, narrative about political micro-targeting. Phil Howard (2006) vividly described a present and future where politicians would use data to "redline" the citizens that received political information, manufacturing attitudes and beliefs, leading to "managed citizenship". In the years since Howard wrote his monumental book, the concerns over micro-targeting have only grown. The explosion of data about the electorate in Western democracies such as Australia, Canada, the UK, and the United States (Howard \& Kreiss, 2010) has triggered deep unease among scholars and privacy advocates alike. Sophisticated voter databases now contain everything from political party data gleaned through millions of interactions with the electorate, public data obtained from state agencies, and commercial marketing information that is bought and sold on international open 
markets. The 2016 US presidential election revealed the new ways that individuals can be profiled, identified, found, tracked, and messaged to on social media platforms such as Facebook and YouTube, which these companies themselves help facilitate (Kreiss and McGregor, 2017).

While it might seem that the micro-targeting practices of campaigns have massive, and undemocratic, electoral effects, decades of work in political communication should give us pause. Although we lack the first-hand data from political campaigns, consultancies, and technology firms such as Facebook to know for sure, previous research tells us that people are seldom the unwitting dupes of strategic political communication. Partisanship shapes much of how people vote and decades of research reveals that it is really hard to change people's minds through campaigns (Kalla \& Broockman, 2017; Henderson \& Theodoridis, 2017). This has large implications for the effectiveness of micro-targeting. For example, Eitan Hersh's (2015) deeply and carefully researched ground-breaking study using data from a major vendor to the US Democratic Party discovers that campaign practitioners find it really hard to persuade voters. This is because political practitioners lack reliable and identifiable data on cross-pressured and low information voters. Given this, campaigns often focus on known voters rather than risk targeting and messaging to the wrong people. Indeed, Hersh reveals that despite hundreds of data points on members of the electorate, it is a small cluster of publically available data - such as turnout history, party identification, and demographic data - that matters far more for predicting vote choice.

The lesson is that micro-targeted campaign ads are likely most effective in the short run when campaigns use them to mobilise identified supporters or partisans, spurring volunteerism, donations, and ultimately turnout - hardly the image of a managed, manipulated, or duped public (Baldwin-Philippi, 2017). Ironically, campaigns often use micro-targeting to further these forms of democratic participation, making appeals to targeted subsets of voters on the basis of the parties and issues they already care about. Campaigns also use micro-targeting in the attempt to decrease voter turnout on the opposing side, sending negative messages to the oppositions' likely voters in the hopes this will make them less excited to turn out for their candidate. But two decades of social science suggests that this can be a risky strategy given that partisans can rally behind their candidate who is being attacked (Dunn \& Tedesco, 2017).

What explains the outsized concerns about micro-targeting in the face of the generally thin evidence of its widespread and pernicious effects? This essay argues that we have anxieties about micro-targeting because we have anxieties about democracy itself. Or, to put it differently, that scholars often hold up an idealised vision of democracy as the standard upon which to judge all political communication. In a world where many scholars and journalists both hope and ardently believe, in the face of all available evidence, that members of the public are fundamentally rational, seek to be informed, and consider the general interest, micro-targeting appears to be manipulative, perverting the capacity of citizens to reason about politics. Meanwhile, for many scholars and journalists, political elites are fundamentally opposed to members of the public, seeking domination or control as opposed to representing their interests. In this world, much of the concern over micro-targeting reads as a classic "third-person effect", where scholars and journalists presume that members of the public are more affected by campaign advertising than they themselves are.

And yet, this idealised version is not how democracy really is, nor necessarily how it should be. The argument of this brief essay is that, as a quantifiable practice premised on strategically identifying targeted groups of voters and crafting messages designed to appeal to them, micro- 
targeting is broadly reflective of the fact that democracy is often partisan, identity-based, and agonistic - in short, political. Following communication scholar Michael Schudson's (1986) study of commercial advertising nearly three decades ago, this essay asks the following questions in the US context: what is the work that micro-targeting does, where does it fit into the political culture, and, what kind of political culture has given rise to it? I argue that microtargeting is only imaginable, and efficacious, in a polity that prizes partisan mobilisation, group solidarity, agonism, and the clash of opposing moral views in its politics. Following from this, I suggest different democratic concerns about micro-targeting that relate to its cultural power to, over time, create a powerful set of representations of democracy that undermines the legitimacy of political representation, pluralism, and political leadership.

\section{THE CULTURAL WORK OF MICRO-TARGETING}

To analyse the role that micro-targeting plays in politics, first we need to understand how and why citizens vote. In their recent book Democracy for Realists, political scientists Christopher Achen and Larry Bartels (2016) offer a sustained critique of what they call the "folk theory" of American democracy. According to this "folk theory" that underlies conceptions of popular sovereignty, Americans have identifiable and consistent policy preferences. During the course of an election, they inform themselves about the policy positions of candidates and make rational decisions as to which best represents their preferences, which in turn leads parties to be responsive to the wishes of the public.

As Achen and Bartels (ibid.) argue, this is a fiction. They outline a "group theory of democracy", where it is social attachments and group identification that largely determine both partisanship and vote choice. Achen and Bartels argue that people see themselves in relation to the groups that they belong to and those that they do not. Identity is so strong, in this account, that it conditions both what partisans believe parties stand for but also their interpretation of facts (ibid., 267; see also Prasad et al., 2009). As Achen and Bartels demonstrate, this identity and group theory of politics has expansive empirical support over seventy years of research which demonstrates, time and again, that people have little knowledge about politics and yet detailed understandings of the social groups that the Democratic and Republican parties are perceived to represent. It is in this context that candidate performances of partisan and social identity become more important for electoral outcomes then the informational content of journalism. Events and candidates make identity more or less salient and strengthen group attachments. During campaigns, parties and candidates work to remind voters of their partisan and social attachments and strengthen them so they are mobilised to participate in the election. As Achen and Bartels (ibid., 311) argue:

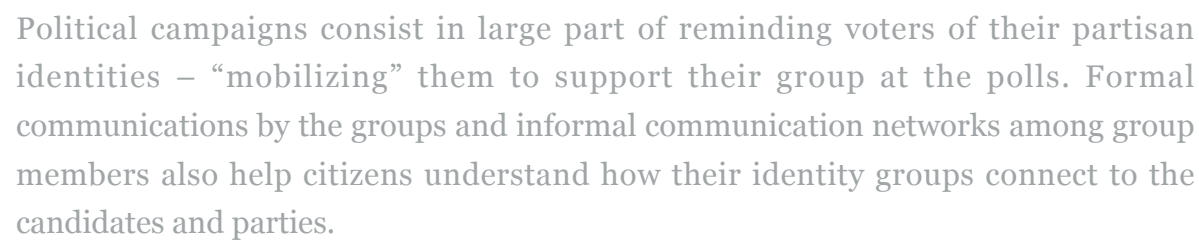

In this context, what is important about political campaigns is this work of communicating the partisan and social identities of candidates to voters. Candidates and their campaigns use micro-targeting, along with other strategic communications, to accomplish this. Micro-targeting 
is both a campaign practice of using data to craft and deliver strategic messages to subsets of the electorate (historically across many different media), and a genre of campaign communications that, much like political advertising more broadly, reinforces and amplifies the partisan, group, and identity conflicts at the heart of US politics. There has been extensive research on how micro-targeting works as a data-driven and quantifiable practice (see, for instance, Karpf, 2016). What these messages do as a genre of campaign communications, however, has received considerably less scrutiny. Drawing on my own previous work in the US context (Kreiss, 2016), the first argument that I develop here is that micro-targeting furthers the mobilisation that Achen and Bartels (2015) identify, primarily through reminding citizens of and shoring up their partisan and group identities. I then discuss the potential democratic consequences of this in a more expansive, cultural sense.

Micro-targeted ads have an aesthetic of what I call "political realism", building on Michael Schudson's work on commercial advertising. In Advertising, The Uneasy Persuasion, Schudson (1986) compared commercial advertising with Soviet realist art (the official state-sanctioned art of the former Soviet Union), arguing that it offers a form of "commercial realism". As commercial realism, commercial advertising "simplifies and typifies" (215); advertising is abstracted, presenting the world as it should be, not as it is, and it exemplifies individuals as members of larger social groups. As it does so, "the aesthetic of capitalist realism - without a masterplan of purposes - glorifies the pleasures and freedoms of consumer choice in defense of the virtues of private life and material ambitions." (ibid., 218)

We can see micro-targeted digital advertising as a cultural form of 'political realism' that reflects, reinforces, and celebrates a political culture, at least in the United States, premised on identity, moral certainty, and mobilisation - not weighty considerations of the general interest or deliberation. Micro-targeted digital content shares a few central characteristics, which I adapt here for politics from Schudson's (1986) work on commercial realism:

- It presents social and political life in simplified and typified ways;

- It presents life as it should become, or for negative ads, as it must not become;

- It presents reality in its larger social significance, not in its actual workings;

- It presents progress towards the future and positive social struggle, or for negative ads, the ideas of the other party as negative steps back into the past. It carries a message of optimism for one partisan side, and takes a stance of pessimism towards political opponents; and,

- It tells us that political conflict is necessary, a clash of different groups and worldviews; moral certainty is assured, political identity is certain, and political agonism is reality.

For example, micro-targeted ads present social life in simplified ways, not presenting actual lives but abstract, stylised ones designed to be rife with larger meaning. A depiction of a farmer's daily work in a campaign ad, for instance, is not about actual events or daily labours, but is meant to be an abstract, simplified, symbol of the American values of hard work and cultivation of the earth and celebration of ordinary people in a democratic society. The farmer here is typified; the campaign ad is not about a real person who farms. The farmer is a representation of the larger social categories, values, and ideas the ad presents as desirable or worthy of emulation for all Americans. At the same time, the two dominant US political parties often stress different themes in their ads, a recognition that they have different visions of what life should be become, what progress is, and what worldviews and moral claims the public should embrace. While doing so, political micro-targeting is inherently pluralist. It reflects a basic claim that "everyone has interests to defend and opinions to advance about his or her own good, or the group's good, or the public good, and every interest was at least potentially a political interest group." (Rosenblum, 2010, 259) 
While it is impossible to know the full range of micro-targeted ads run during the course of an election cycle, consider some of the examples culled from the non-profit and non-partisan Democracy in Action website that chronicles US campaigns and the Hillary for America Design 2016 website that compiles the creative design from the campaign. To start, much of political micro-targeting is about building campaign databases by finding supporters online, signing them up for the cause through email, and repeatedly messaging them to enlist them in becoming a volunteer or a donor.

Take, for instance, the declarative "I am a Hillary Voter" digital ad (see Figure 1), presumably (but also logically) directed (although we can never know for sure) at the candidate's supporters. What separates micro-targeted political ads from their mass broadcast counterparts is the data that lies behind them: campaigns can explicitly try to find and send messages to their partisan audiences or intra-party supporters, linking the names in their databases to identities online or on social media platforms such as Facebook. Campaigns can also try to find additional partisans and supporters by starting with the online behaviours, lifestyles, or likes or dislikes of known audiences and then seeking out 'look-alike audiences', to use industry parlance. And, what people do when they see these ads is quantified in terms of their performance, measured through things such as engagement and click-throughs. Micro-targeting is about mobilisation through conveying and building social solidarity. While there is much concern over candidates speaking out of both sides of their mouths to the electorate through hyper-targeted digital ads, likely far more often campaigns use micro-targeting to provide occasions for social identification and group belonging, conveying and constructing the sense of shared identity and group membership at the heart of politics. The "Wish Hillary a Happy Birthday" ad captures this (see Figure 2). Not only is this appeal directed at supporters (what Republican will want to wish Hillary a happy birthday after all), it constructs a sense of what social identification with Hillary Clinton means: motherhood, family, warmth, care, and nurturing. 


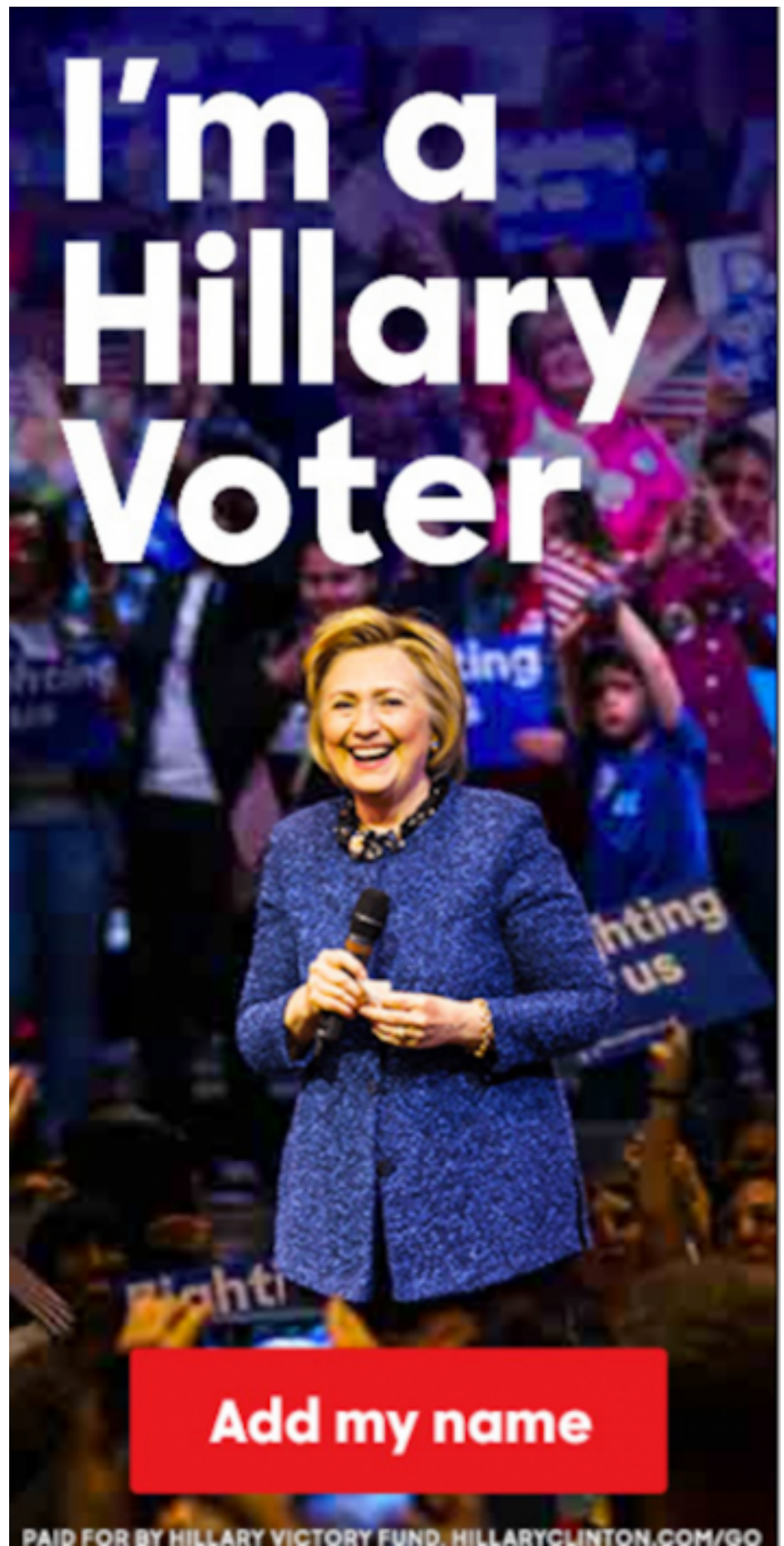

Figure 1: Hillary Clinton digital campaign advertisements 


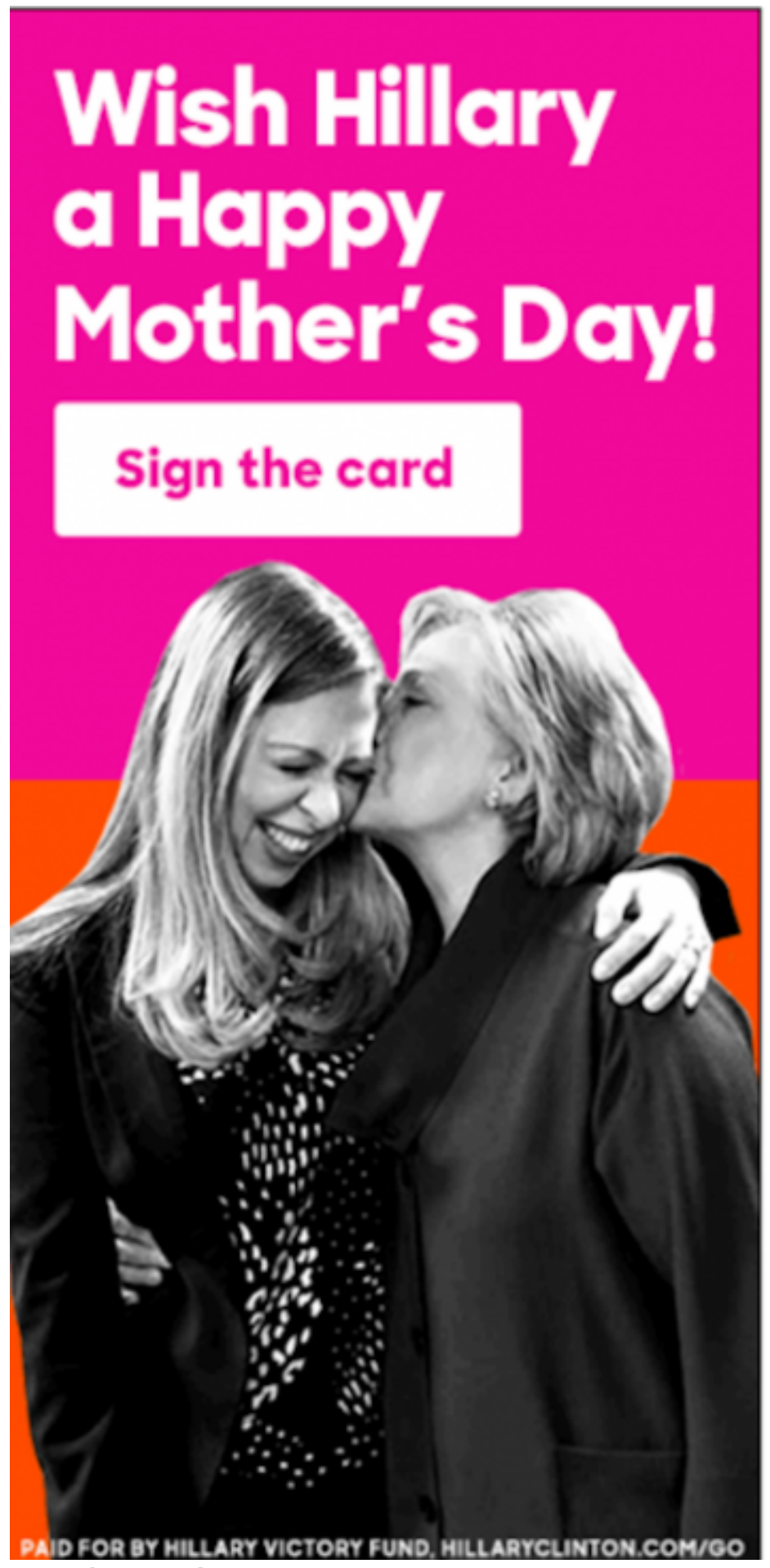

Figure 2: Hillary Clinton digital campaign advertisement

Source: Hillary for America Design 2016

Micro-targeting is also about the marking of difference. This is, perhaps, the most common trope in micro-targeted digital campaign ads. Campaigns look to not only establish the cultural meaning of their candidates and supporters, but also that of their opposition (Alexander, 2010). Donald Trump's ads during the 2016 election reflected his rhetoric from the campaign trail in stressing themes of safety and security, in addition to the need to draw boundaries around civic incorporation (i.e., who should be allowed to be a citizen). For Hillary Clinton, micro-targeted ads were celebrations of diversity and multi-culturalism, especially the empowerment of women 
and racial and ethnic minorities. Political advertisements attempt to connect the candidates they promote with the demographic and social groups they seek to represent (in the United States this is at times drawn on racial and ethnic terms: whites for Republicans and a more diverse coalition for Democrats, see the discussion in Grossmann \& Hopkins, 2016, 43-45).

In this, micro-targeting reflects and reinforces political agonism, the clash of competing social groups, interests, and values. Through micro-targeting, candidates stake out their claim to be on the civil side of the moral binary of the political sphere and strive to paint their opponents as anti-civil (Alexander, 2010). More colloquially, micro-targeted advertisements offer the beautiful affirmation of our values and the sharp critique of those of our opponents. Hillary Clinton's campaign, for instance, clearly sought to portray Trump in terms of anti-civil racism, xenophobia, and sexism. And, the campaign used issues, such as abortion rights, and values, such as autonomy and choice, to build group identity and social solidarity around opposition to Trump: "Let's stand together, join millions of women" (see Figure 3). This Facebook ad pits Clinton and her supporters against Trump and his supporters. Trump, in turn, combined nationalist and security appeals with an implicit construction of the American body politic in white identity terms (Figure 4). These ads capture the reality that political conflict is not only inevitable, but necessary: there are opposing views in politics on fundamental questions such as life, autonomy, and country. The audiences for these ads are not being presented with information to help them make up their own minds, they are being invited into a political struggle with clear opposing worldviews and moral values (see Figure 5). This is why mobilisation ads are directed towards identity-congruent audiences.

Donald Trump just said "there has to be some form of punishment" for women who get an abortion.

Let's stand together to protect a woman's right to make her own health decisions.

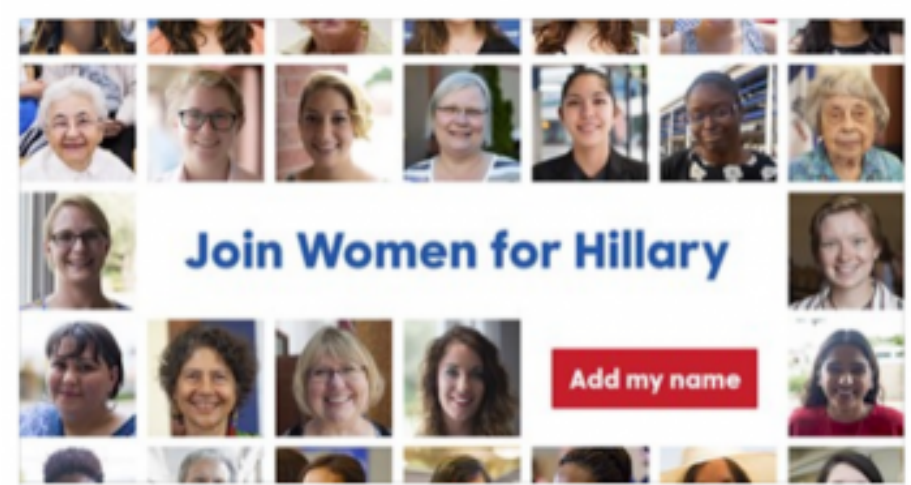

Join millions of women for Hillary and stop Trump Add your name today. 


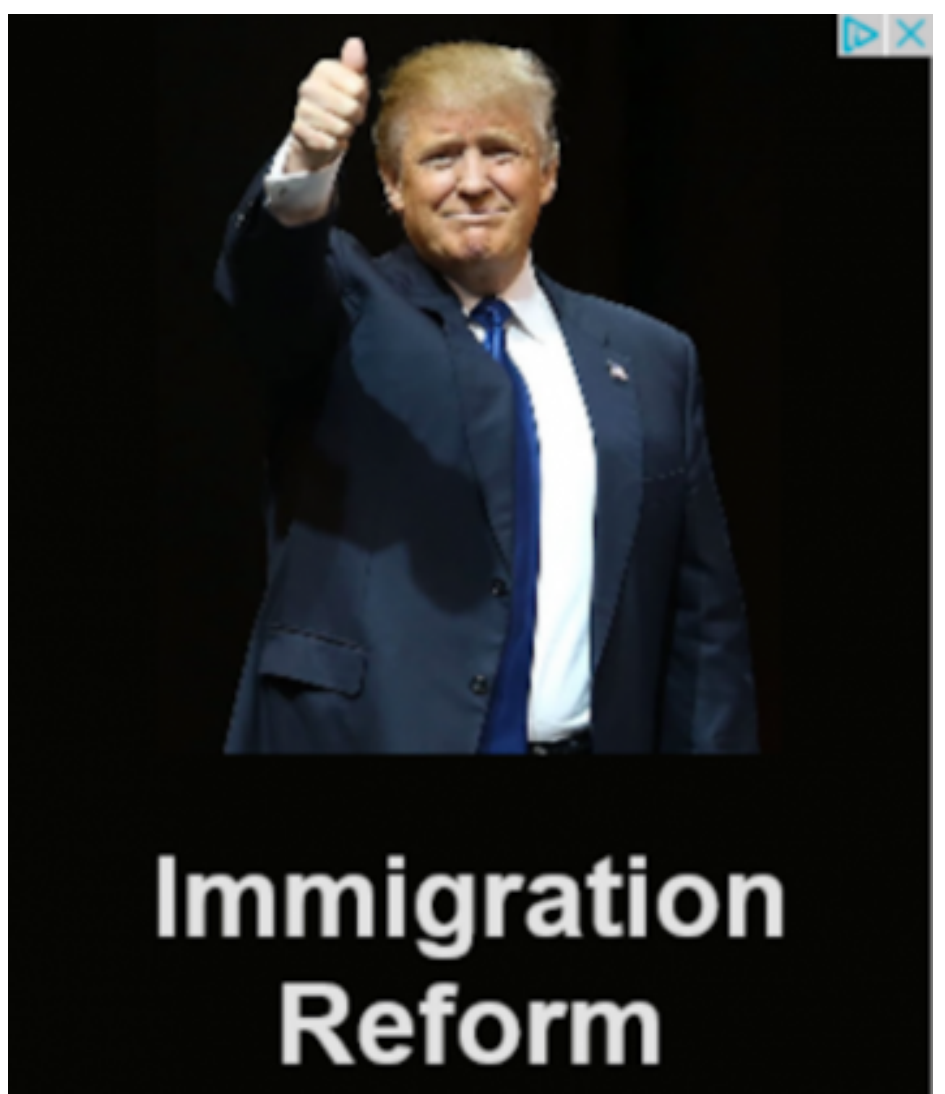

We don't have a country without borders. We need to BUILD A WALL.

\section{TRUMP \\ MAKE AMERICA GREAT AGAIN!}

\section{Support Now}

Figure 4: Donald Trump digital advertisement

Source: Democracy in Action 


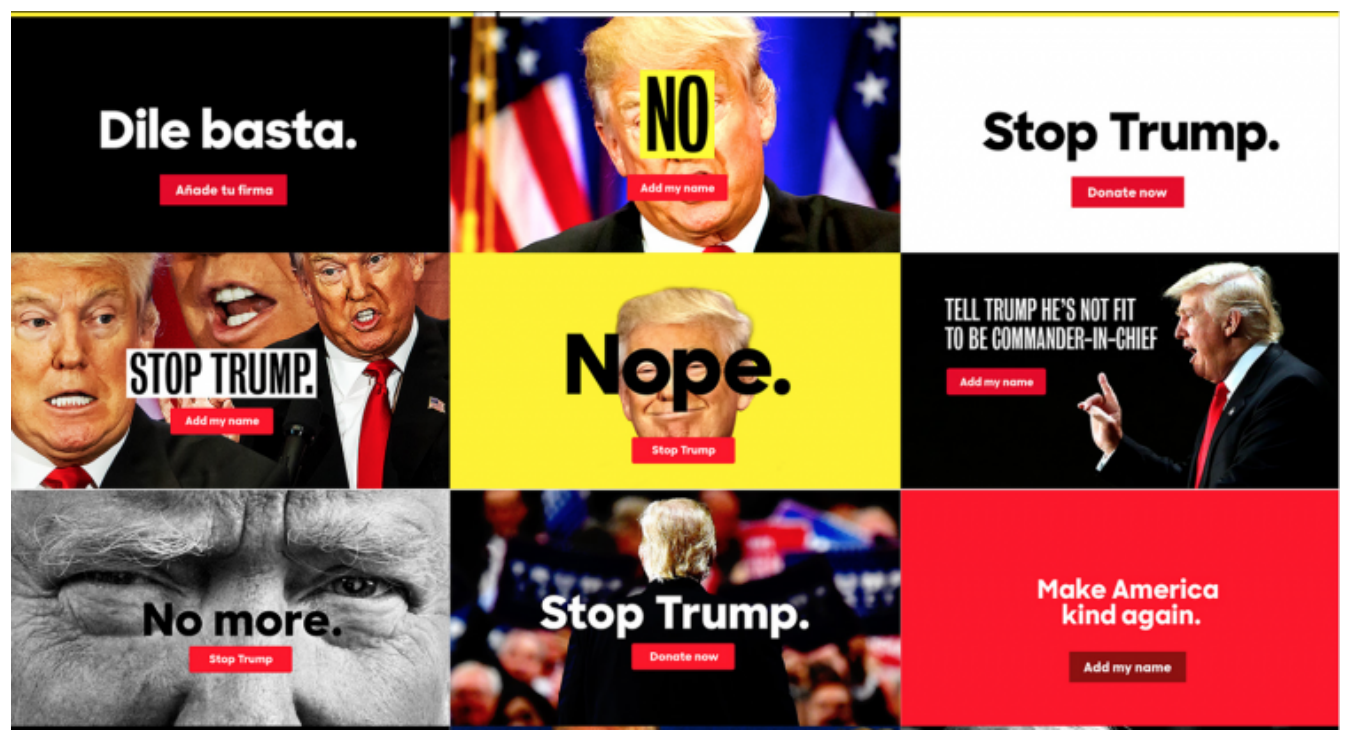

Figure 5: Anti-Trump Hillary Clinton digital advertisements

Source: Hillary for America Design 2016

In these advertisements, it is also clear that micro-targeted ads present life as it should become, or as it must not become, linking the preferred candidate and political party with a civil vision of the future and the opposition with an anti-civil vision of the future, to use Alexander's (2010) framework. As an example, for Ted Cruz (see Figure 6), the opposing side wants to infringe on the Bill of Rights, the fundamental liberty of Americans to defend their lives, liberties, families, and properties. Candidates run these issue ads to stake out their stance on the conflicting values, visions of the good life, plans for the future, and ends that are desirable in politics - whether it is embracing the freedom and security of gun rights for American Republicans or autonomy and choice in the context of reproductive rights for Democrats. These appeals are designed to mobilise the committed around the candidate's vision of America's past and future - they are designed for a world where we are sure of who we are and committed to our values and the ends we pursue.

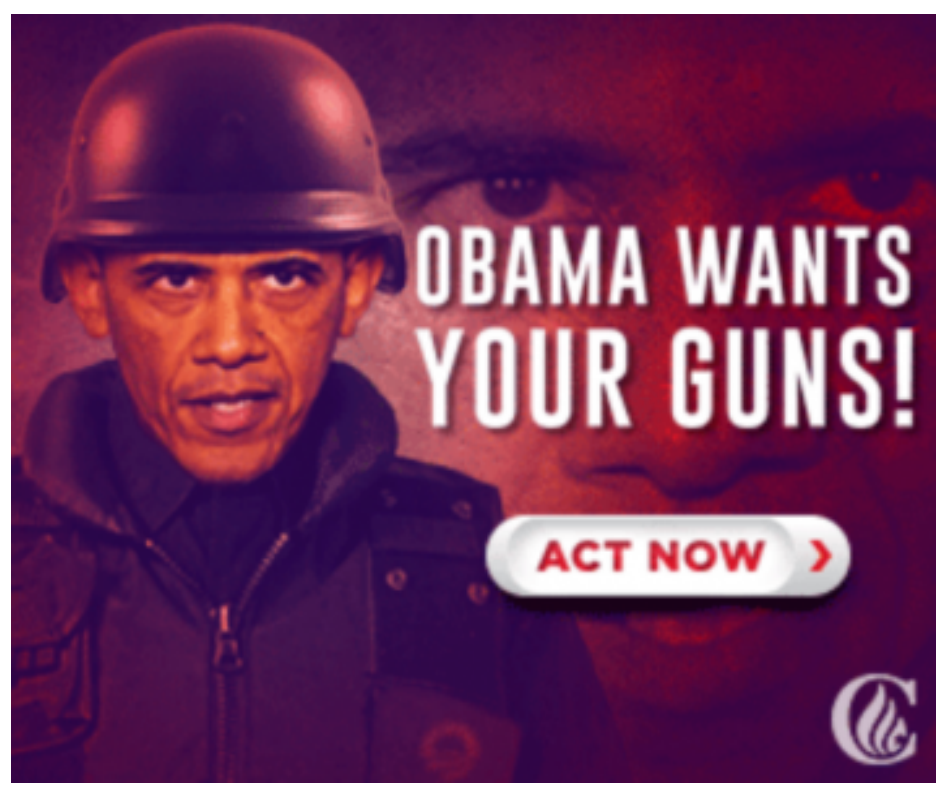

Figure 6: Ted Cruz digital campaign advertisement

Source: Democracy in Action 


\title{
CONCLUSION: DEMOCRATIC ANXIETIES
}

I believe that there is such democratic anxiety about micro-targeting because citizens are supposed to be independent, autonomous, and rational. Micro-targeted advertising works to reinforce group identities and solidarity, mobilise partisans, and further the clash of political values. These things are all suspect from the perspective of the powerful and potent "folk theory" of democracy, as Achen and Bartels phrase it. As these realists argue, however, it's far better to grapple with the reality of group-based democracy, with its attendant ingrained social allegiances and conflicts over values and power, rather than wishing for a transcendent and pure form of democracy without politics. These authors argue that we need to make peace with conflictual and competitive forms of group-based and pluralistic democracy premised on institutionally organised opposition. As Achen and Bartels $(2015,318)$ conclude:

\begin{abstract}
Freedom is to faction what air is to fire, Madison said. But ordinary citizens often dislike the conflict and bickering that comes with freedom. They wish their elected officials would just do the people's work without so much squabbling amongst themselves. They dislike the compromises that result when many different groups are free to propose alternative policies, leaving politicians to adjust their differences. Voters want "a real leader, not a politician," by which they generally mean that their own ideas should be adopted and other people's opinions disregarded, because views different from their own are obviously self-interested and erroneous. To the contrary, politicians with vision who are also skilled at creative compromise are the soul of successful democracy, and they exemplify real leadership.
\end{abstract}

My own view is that micro-targeting comes in the necessary service of this "conflict and bickering”. At its normative best, micro-targeting strengthens the hands of opposing factions, enabling them to identify and mobilise partisans to their cause, providing them with resources in terms of boots on the ground and money in the coffers. When opposing politicians and parties square off, they carry these resources into battle trying to advance their agendas or win concessions for their side. Compromise may be harder in a world of stronger factions, their hands steadied by the resources that micro-targeting can deliver, but that does not make compromise any less necessary or essential.

On the other hand, there are reasons for democratic concern about micro-targeting, but they look a bit different from narratives about public manipulation. Schudson $(1986,232)$ concludes that "advertising does not make people believe in capitalist institutions or even in consumer values, but so long as alternative articulations of values are relatively hard to locate in the culture, capitalist realist art will have some power." I suspect that the same is true of political micro-targeting. The cultural power of political micro-targeting, but also political advertising more generally, lies in its creation of a set of ready-to-hand representations of democracy that citizens can express easily and fall back on. Taken to its extreme in a polarized political climate, micro-targeting can work to undermine the legitimacy of conflicts over opposing values and claims in democratic life. For example, in an undemocratic political culture micro-targeting can portray the other side as crooked and dangerous to the polity, political compromise as selling out, political expertise and representation as not to be trusted, and partisans' own beliefs and identities as the only legitimate ones, not simply those among many in a pluralistic democracy. Micro-targeting also melds symbolic and social power in new ways, culturally legitimating and 
furthering the fortunes of autonomous and independent candidates, divorced from their parties and taking their appeals directly to voters (see Hersh, 2017). 


\section{REFERENCES}

Achen, C. H., \& Bartels, L. M. (2016). Democracy for realists: Why elections do not produce responsive government. Princeton University Press.

Alexander, J. C. (2010). The performance of politics: Obama's victory and the democratic struggle for power. Oxford University Press.

Baldwin-Philippi, J. (2017). The myths of data-driven campaigning. Political Communication, 34(4), 627-633. doi:10.1080/10584609.2017.1372999

Dunn, S., \& Tedesco, J. C. (2017). Political Advertising in the 2016 Presidential Election. In The 2016 US Presidential Campaign (pp. 99-120). Palgrave Macmillan, Cham.

Grossmann, M., \& Hopkins, D. A. (2016). Asymmetric politics: Ideological Republicans and group interest Democrats. Oxford University Press.

Hersh, E. D. (2015). Hacking the electorate: How campaigns perceive voters. Cambridge University Press.

Hersh, E. D. (2017). Political Hobbyism: A Theory of Mass Behavior.

Howard, P. N., and Kreiss, D. (2010). Political Parties and Voter Privacy: Australia, Canada, the United Kingdom, and United States in Comparative Perspective. First Monday, 15(12).

Howard, P.N. (2006) New Media Campaigns and the Managed Citizen. Cambridge University Press.

Kalla, J. L., \& Broockman, D. E. (2017). The Minimal Persuasive Effects of Campaign Contact in General Elections: Evidence from 49 Field Experiments. American Political Science Review, 119. doi:10.1017/Sooo3055417000363

Karpf, D. (2016). Analytic activism: Digital listening and the new political strategy. Oxford University Press.

Kreiss, D., \& McGregor, S.C. (2017). Technology Firms Shape Political Communication: The Work of Microsoft, Facebook, Twitter, and Google With Campaigns During the 2016 US Presidential Cycle. Political Communication, 1-23. doi:10.1080/10584609.2017.1364814

Kreiss, D. (2016). Prototype politics: Technology-intensive campaigning and the data of democracy. Oxford University Press.

Henderson, J. A., \& Theodoridis, A. G. (2017). Seeing Spots: Partisanship, Negativity and the Conditional Receipt of Campaign Advertisements. Political Behavior, 1-23.

doi:10.1007/s11109-017-9432-6

Prasad, M., Perrin, A. J., Bezila, K., Hoffman, S. G., Kindleberger, K., Manturuk, K., ... Payton, A. R. (2009). The Undeserving Rich: "Moral Values" and the White Working Class. Sociological Forum, 24(2), 225-253. doi:10.1111/j.1573-7861.2009.01098.x

Rosenblum, N. L. (2010). On the side of the angels: an appreciation of parties and partisanship. Princeton University Press. 
Schudson, M. (1986). Advertising, the uneasy persuasion: its dubious impact in American Society. New York: Routledge. 